\title{
Guidelines for perioperative management of apixaban. Can we trust them?
}

\author{
Cristina Monteserín-Matesanz*, Jorge L. González-Cantero, Francisco J. González-Moraga, \\ Guillermo Sánchez-Pedrosa, María Lema-Tomé, Francisco J. Sanz-Fernández and \\ Ignacio Garutti-Martínez \\ Hospital General Universitario Gregorio Marañón, Madrid, Spain
}

\begin{abstract}
Direct oral anticoagulants, such as apixaban, have a predictable dose-response and few interactions with other drugs and food; hence, they do not require routine coagulation monitoring. We report a woman on long-term treatment with apixaban undergoing elective surgery. Although apixaban was suspended $24 \mathrm{~h}$ before, we noticed residual anticoagulation just prior the intervention. Given the lack of robust evidence to guide perioperative management of apixaban, it could be an increased risk of hemorrhagic complications if normalization of the coagulation system is not checked. We propose anti-factor Xa levels' determination in every patient on chronic therapy with apixaban before programmed surgery.
\end{abstract}

Key words: Direct oral anticoagulants. Apixaban. Anti-factor Xa.

\section{Guías para el manejo perioperatorio de apixaban. ¿Podemos fiarnos?}

\section{Resumen}

Los anticoagulantes orales directos, como el apixaban, tienen una dosis-respuesta predecible con pocas interacciones fármaco-alimenticias y no requieren monitorizar la coagulación. Presentamos a una mujer en tratamiento con apixaban propuesta para cirugía electiva. Aunque el apixaban fue suspendido 24 horas antes, detectamos una anticoagulación residual justo antes de la intervención. Dada la falta de evidencia robusta para guiar el manejo perioperatorio del apixaban, puede existir un mayor riesgo de complicaciones hemorrágicas si no se confirma la normalización de la coagulación. Proponemos la determinación del nivel de anti-factor Xa para pacientes en tratamiento crónico con apixaban previo a una cirugía programada.

Palabras clave: Anticoagulantes orales directos. Apixaban. Anti-factor Xa.

Correspondence:

${ }^{*}$ Cristina Monteserín-Matesanz, mail: cristinamonteserinmatesanz@gmail.com DOI: 10.24875/RAA.18000009

Available online: 05-02-2019 Rev Argent Anestesiol. 2018;76(2):89-92 www.revistaargentinaanestesiologia.com
por Permanyer México SA de CV. Este es 0370-7792 @ 2018 Federación Argentina de Asociaciones, Anestesia, Analgesia y Reanimación. Publicado por Permanyer México SA de CV. Este es
un artículo Open Access bajo la licencia CC BY-NC-ND (http://creativecommons.org/licenses/by-nc-nd/4.0/). 


\section{Introduction}

Direct oral anticoagulants (DOACs) are drugs with predictable pharmacokinetic properties including fast onset of effect, short elimination half-lives, and few food or drug interactions, so routine laboratory monitoring is not required $^{1,2}$. An example of these DOAC is apixaban, which acts as a direct factor $\mathrm{Xa}$ inhibitor that is specially indicated for patients with impaired renal function and reduced creatinine clearance $(\mathrm{CrCl})$. No dose adjustment is required in patients with mild $(\mathrm{CrCl} 50-80 \mathrm{~mL} / \mathrm{min})$ or moderate $(\mathrm{CrCl} 30-50 \mathrm{~mL} / \mathrm{min})$ renal impairment.

According to its pharmacodynamic profile, administration of apixaban results in a dose-dependent prolongation in the prothrombin time (PT), international normalized ratio (INR), and activated partial thromboplastin time (aPTT). Although routine laboratory monitoring is not required for patients undertaking apixaban, there are limited data regarding effective methods used for measuring its anticoagulant activity, which could be really valuable in certain clinical situations, including patients who should undergo elective surgery while on long-term therapy with apixaban such as the case we report here. We decided to monitor the pre-operative coagulation profile of our patient, and we noticed an unexpected result.

Conventionally, the gold standard method for determining apixaban plasma concentration is liquid chromatography-mass spectrometry (LC-MS), but it is complex and time-consuming, so that it cannot be used in the usual laboratory setting, which implies the need for other laboratory assays that allow a fast and accurate determination of the coagulation status. These more specific assays include the factor Xa chromogenic assay. Although LC-MS measures plasma drug mass and factor $X a$ assays determines the anti-factor $\mathrm{Xa}$ activity, there is good concordance and reproducibility between both methods ${ }^{3}$, which permits to set up a concentration-dependent relationship between anti-factor Xa activity and apixaban plasma levels. The factor Xa chromogenic assay is available in many hospital laboratories, which makes it an attractive way of coagulation monitoring; however, there is a lack of validated therapeutic plasma levels just like a lack of known plasma concentration ranges from which the thrombotic or hemorrhagic risk is increased.

\section{Clinical case}

A 73-year-old woman (weight $88 \mathrm{Kg}$, height $160 \mathrm{~cm}$, and body mass index $34.38 \mathrm{Kg} / \mathrm{m}^{2}$ ) with no known drug allergies and with a past medical history of hypertension, dyslipemia, non-insulin-dependent diabetes mellitus, thyroid dysfunction, paroxystic atrial fibrillation, and an oncologic process in the parotid gland was presented. She received chronic treatment with atenolol, enalapril, atorvastatin, metformin, linagliptin, levothyroxine, apixaban $5 \mathrm{mg} / 12 \mathrm{~h}$, amiodarone, and omeprazole. The Department of Maxillofacial Surgery proposed her for an elective cervical lymph node excision.

At the pre-operative visit to the anesthesiology, she was calculated to have a moderate thrombotic risk $\left(\mathrm{CHA}_{2} \mathrm{DS}_{2}-\right.$ $\mathrm{VASC}=4$ points) and low hemorrhagic risk (minor surgery). Her blood test showed the following parameters: hemoglobin $11.2 \mathrm{~g} / \mathrm{dL}$, platelets $255,000 / \mu \mathrm{L}$, creatinine $0.94 \mathrm{mg} / \mathrm{dL}, \mathrm{CrCl} 58 \mathrm{~mL} / \mathrm{min}, \mathrm{PT} 13.3 \mathrm{~s}$, INR 1.11, aPTT $42.1 \mathrm{~s}$, aPTT ratio 1.4, and fibrinogen $610 \mathrm{mg} / \mathrm{dL}$. It was decided that apixaban should be discontinued for $24 \mathrm{~h}$ without instauration of any bridging therapy.

The day of the surgical intervention, after suspending apixaban for at least $24 \mathrm{~h}$, coagulation parameters were as follows: PT $12.2 \mathrm{~s}$, INR 1.1, aPTT $39.3 \mathrm{~s}$, aPTT ratio 1.27, fibrinogen $395 \mathrm{mg} / \mathrm{dL}$, and anti-factor-Xa $0.67 \mathrm{U} / \mathrm{mL}$. Our laboratory reference value for anti-factor-Xa is $<0.01 \mathrm{U} / \mathrm{mL}$, so surgery was cancelled due to the presence of residual anticoagulant effect.

At a new date, apixaban was suspended $48 \mathrm{~h}$ before surgery with no bridging therapy again. Coagulation test extracted just before the surgical intervention showed the following results: PT $12.1 \mathrm{~s}$, INR 1.02, aPTT $36.2 \mathrm{~s}$, aPTT ratio 1.21, fibrinogen $483 \mathrm{mg} / \mathrm{dL}$, and anti-factor-Xa $0.05 \mathrm{U} / \mathrm{mL}$. Surgery took place under general anesthesia conditions without any incidence during the intraoperative period. Likewise, the immediate post-operative period was uneventful and the patient initiated pharmacologic prophylaxis with enoxaparin $40 \mathrm{mg} / 24 \mathrm{~h}$ the day after surgery.

Apixaban was restarted after the $7^{\text {th }}$ post-operative day. A telephone call done 1 month after surgery corroborated that the patient had not suffered any thrombotic or hemorrhagic complication in relation to the suspension and reintroduction of apixaban.

\section{Discussion}

Perioperative management of patients on long-term treatment with DOAC continues being controversial. Usually, DOAC is discontinued before surgery to have a minimal anticoagulant effect at the time of the intervention, but it is imperative to take into account the surgical hemorrhagic risk (Table 1) opposite to the patient thrombotic risk (Table 2) before stopping any 
Table 1. Hemorrhagic risk classification according to surgery proposed by the Spanish Forum on Anticoagulants and Aaesthesia ${ }^{4}$

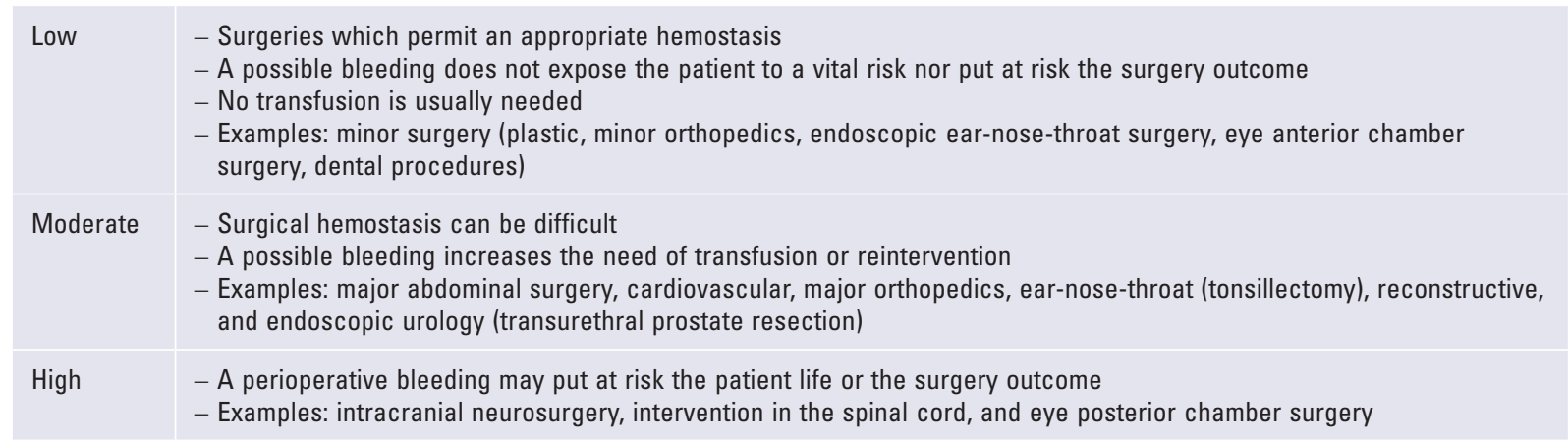

Table 2. Thrombotic risk classification according to patient characteristics proposed by the Spanish Forum on Anticoagulants and Anesthesia ${ }^{4}$

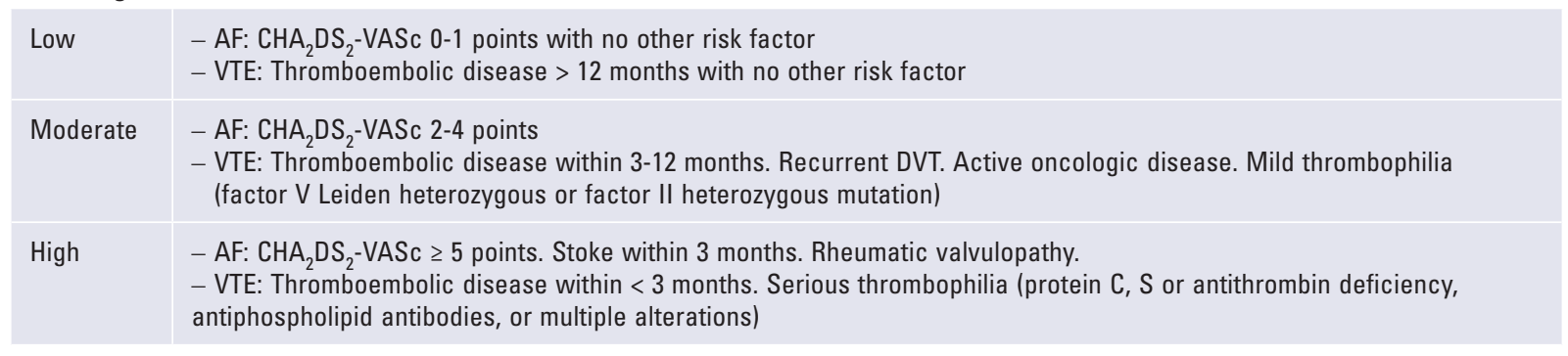

AF: atrial fibrillation; DVT: deep vein thrombosis; VTE: venous thromboembolism, $\mathrm{CHA}_{2} \mathrm{DS}_{2}$-VASc puntuation: congestive heart failure, hypertension,

age $\geq 75$ years (doubled), diabetes melitus, stroke (doubled), vascular disease, age 65-74 years, sex female.

anticoagulant medication ${ }^{4,5}$. The time interval of the DOAC treatment suspension is based on the pharmacokinetic characteristics of the drug, mostly its elimination half-life. Assuming first-order elimination kinetics, after one half-life, $50 \%$ of the anticoagulant effect will still remain, $25 \%$ after two half-lives, $12.5 \%$ after three half-lives, $6.25 \%$ after four half-lives, and $3.125 \%$ after five half-lives. In the case of apixaban and knowing that its elimination half-life is of $8-15 \mathrm{~h}$ in healthy young people, suspension of the drug the day before surgery with omission of two doses would theoretically be enough to eliminate its anticoagulant effect.

According to expert opinion, current perioperative management of apixaban is based on its pharmacology, although there is a lack of clinical studies which allow setting up a safety approach for managing patients treated with DOAC who undergo programmed surgery. To face this gap of knowledge in relation to the perioperative management of apixaban, several recommendations have emerged. Most working groups consider a long discontinuation of 5 days before any surgery as the safest option ${ }^{4,6}$ so that a minimal residual anticoagulant effect could be guaranteed even in elderly patients (> 65 years) with renal impairment or with other conditions associated with delayed drug elimination. Such prolonged suspension is also recommended for surgeries with moderate or high hemorrhagic risk. Keeping in mind that this pre-operative discontinuation of apixaban increases the patient thrombotic risk, it should be administered a bridging therapy with heparins. However, it has also been proposed a short pre-operative discontinuation of $24 \mathrm{~h}$ before procedures with a low hemorrhagic risk $^{6}$, which would permit to obviate the need for bridging therapy.

According to our hospital protocol for the perioperative management of anticoagulated patients and on the light of the current published recommendations ${ }^{6}$, our patient underwent a short (24 h) pre-operative interruption of apixaban. We took this option since she was proposed for a minor surgery and her renal function was not altered. Besides, although she concomitantly used several other medications, none of them is included between the listed drugs with a recognized interaction with apixaban? In spite of it, her pre-operative anti-factor Xa levels were excessively elevated, indicating that the anticoagulant effect of the drug was still present, which would have put our patient at an increased risk of hemorrhagic complications if the surgery had took place under such 
conditions. Anti-factor Xa levels as high as $0.67 \mathrm{U} / \mathrm{mL}$ are dangerous and non-emergent surgery should not be performed with so elevated levels.

Although many countries have their own recommendations for the management of the DOAC, most of them are just based on expert opinion and, unfortunately, there is a lack of well-designed clinical trials to support robust guidelines for the perioperative discontinuation of apixaban. When facing a patient on chronic treatment with apixaban, it is necessary to assess his/her coagulation status before elective surgery since clinicians can find themselves in situations where a normal pre-operative coagulation cannot be guaranteed, exposing patients to a potentially increased bleeding risk. The best way to reassure a safe management for patients through the perioperative period is determining pre-operative apixaban concentration in plasma, but, in clinical practice, anti-factor Xa levels measurement is the best approach to control apixaban plasma concentration $^{8,9}$. Should anti-factor Xa levels be elevated, such as in our patient, non-emergent surgeries can be delayed until apixaban concentration reaches a safer range. Surgery can be done under conditions of safety when the DOAC concentration is below an accepted threshold level. Hence, to rule out any additional bleeding risk associated with the presence of high residual drug levels, we propose pre-operative anti-factor Xa levels determination in every patient undergoing elective surgery while on therapy with apixaban.

Facing up to people on long-term treatment with DOAC is constantly increasing. The knowledge of these new drugs' pharmacology would let physicians to better understand the coagulation alterations associated with their consumption,, which is primarily outstanding for surgical patients. The case we have reported here perfectly reflects this situation. The patient underwent a safer surgery due to our pre-operative coagulation monitoring. We recommend carrying out coagulation controls before any non-emergent surgical intervention in patients on therapy with DOAC as a way of optimizing patients if necessary.

\section{Conclusions}

There are circumstances where the measurement of the DOAC plasma concentration is useful for ensuring the highest safety for patients. In the case of apixaban, factor Xa chromogenic assay can be used to reliably determine its plasma concentration. This determination is needed to verify that its plasma levels are low enough to safely undergo elective surgery, without an increased risk of bleeding due to a residual anticoagulant effect.

Almost all anesthetics societies have their own guidelines for managing patients on long-term with DOAC treatment, there is still an important gap of knowledge. Although there is not a robust evidence for the perioperative management of patients chronically treated with apixaban and while further information is published, safety anti-factor Xa levels ought to be verified to confront non-emergent surgery.

\section{Ethical disclosures}

Protection of human and animal subjects. The authors declare that no experiments were performed on humans or animals for this study.

Confidentiality of data. The authors declare that they have followed the protocols of their work center on the publication of patient data.

Right to privacy and informed consent. The authors have obtained the written informed consent of the patients or subjects mentioned in the article. The corresponding author is in possession of this document.

\section{References}

1. Garcia D, Libby E, Crowther MA. The new oral anticoagulants. Blood. 2010;115:15-20.

2. Eikelboom JW, Weitz JI. New anticoagulants. Circulation. 2010;121: 1523-32.

3. Gouin-Thibault I, Flaujac C, Delavenne X, et al. Assessment of apixaban plasma levels by laboratory tests: suitability of three anti-xa assays. A multicentre french GEHT study. Thromb Haemost. 2014;111:240-8.

4. Llau JV, Ferrandis R, Castillo J, et al. Management of direct action oral anticoagulants in the peri-operative period and invasive techniques. Rev Esp Anestesiol Reanim. 2012;59:321-30.

5. Levy JH, Faraoni D, Spring JL, Douketis JD, Samama CM. Managing new oral anticoagulants in the perioperative and intensive care unit setting. Anesthesiology. 2013;118:1466-74.

6. Sié P, Samama CM, Godier A, et al. Surgery and invasive procedures in patients on long-term treatment with direct oral anticoagulants: thrombin or factor-xa inhibitors. Recommendations of the working group on perioperative haemostasis and the french study group on thrombosis and haemostasis. Arch Cardiovasc Dis. 2011;104:669-76.

7. Walenga JM, Adiguzel C. Drug and dietary interactions of the new and emerging oral anticoagulants. Int J Clin Pract. 2010;64:956-67.

8. Lippi G, Favaloro EJ. Recent guidelines and recommendations for laboratory assessment of the direct oral anticoagulants (DOACs): is there consensus? Clin Chem Lab Med. 2015;53:185-97.

9. Castellone DD, Van Cott EM. Laboratory monitoring of new anticoagulants. Am J Hematol. 2010;85:185-7. 